\title{
QUALIDADE DE VIDA NO TRABALHO E ADOECIMENTO NO COTIDIANO DE DOCENTES DO ENSINO SUPERIOR
}

\author{
Alex Pizzio* \\ KarLA KLEIN ${ }^{* *}$
}

RESUMO: O objetivo deste artigo é divulgar os resultados de um estudo sobre a Qualidade de Vida no Trabalho (QVT) de docentes do Ensino Superior. A metodologia aplicada foi o estudo de caso em uma universidade federal brasileira oriunda da atual política de expansáo do ensino superior. Nessa perspectiva, selecionou-se, como objeto de estudo, a Universidade Federal do Tocantins (UFT), pelo fato de essa instituição inserir-se em uma das regióes centrais para a política de expansão, ser a instituição de maior crescimento em número de docentes e cursos entre as universidades federais da regiáo Norte do país e por apresentar estrutura multicampi em número de sete. $\mathrm{O}$ estudo desenvolveu-se durante o segundo semestre de 2012, quando foram aplicados 130 questionários de avaliação da QVT com escalas psicométricas de mensuração do tipo likert de 10 pontos. Foram utilizados o software SPSS para o tratamento de questôes fechadas e o software NVivo 10 para as questôes abertas. Por fim, os dados obtidos com os questionários foram cruzados com os dados de adoecimentos obtidos no SIASS/UFT. Os resultados demonstram que quanto maior a integração do projeto de vida do docente à instituiçâo, maior é a QVT, mesmo em condiçôes de trabalho desfavoráveis. Por outro lado, quanto maior for o distanciamento do projeto pessoal/coletivo dos objetivos institucionais, menor se torna a QVT. Fatores relacionais têm implicação direta na QVT dos docentes e a adoção de Políticas de Promoção e Suporte à fixação dos docentes contribui para a redução do adoecimento dos mesmos.

Palavras-chave: ReUni; Trabalho docente; Qualidade de vida no trabalho; Instituiçóes de Ensino Superior.

\footnotetext{
* Universidade Federal de Tocantins, Programa de Pós-Graduação em Desenvolvimento Regional, Palmas, TO., Brasil. E-mail de contato: alexpizzio@gmail.com.

** Universidade Federal de Tocantins, Núcleo em Desenvolvimento Regional, Palmas, TO., Brasil. E-mail de contato: karlaklein@mail.uft.edu.br.
} 


\section{QUALITY OF WORK LIFE AND ILLNESS IN THE DAILY LIVES OF HIGHER EDUCATION PROFESSORS}

ABSTRACT: The purpose of this article is to disseminate the results of a study on the Quality of Work Life (QWL) of professors. The methodology used in the study was a case study carried out in a Brazilian Federal University which originated from the current policy for the expansion of higher education. In this perspective, the Federal University of Tocantins (UFT) was selected as the object of study, due to the fact that it is located in one of the central regions aimed by the expansion policy; it is the institution which has shown the highest growth in the number of teachers and courses among the Federal universities in the Northern Region of the country and it has several campuses (seven in total). The study was carried out during the second half of 2012, when 130 QWL evaluation questionnaires (10-point Likert-type scale) were applied. The SPSS software was used for the treatment of closed questions and the NVivo 10 software for open questions. Finally, the data obtained from the questionnaires were cross-referenced with illness data obtained from SIASS/UFT. The results show that the greater the integration of the professor's life project with the institution, the greater the QWL, even in unfavorable working conditions. On the other hand, the greater the distance of the personal/collective project from the institutional objectives, the lower the QWL. Relational factors have direct implications on the QWL of teachers and the adoption of Policies for Promotion and Support for the permanence of teachers contributes to the reduction of illnesses.

Keywords: ReUni; Higher education professors; Quality of work life; Higher education institutions.

\section{QUALITÉ DE VIE AU TRAVAIL ET LA MALADIE DANS LA VIE QUOTIDIENNE DES ENSEIGNEMENTS UNIVERSITAIRES}

RÉSUMÉ: Le but de cet article est de diffuser les résultats d'une étude sur la qualité de vie au travail (QVT) des enseignants dans l'enseignement supérieur. La méthodologie utilisée est l'étude de cas dans une université brésilienne dérivée de la politique fédérale actuelle pour le développement de l'enseignement supérieur. De ce point de vue, a été choisi comme objet d'étude, l'Université Fédérale de Tocantins (UFT), $\mathrm{du}$ fait que cette institution se trouve dans une des régions centrales de la politique d'expansion, l'imposition d'une plus forte croissance du nombre d'enseignants et des cours entre les universités fédérales de la région Nord du pays et aussi par sa structure multicampi en étant au nombre de sept. L'étude a été réalisée au cours de la seconde moitié de 2012, lorsqu'on a soumis 130 questionnaires évaluant la QVT avec échelles psychométriques de mesure du type Likert à 10 points. Deux logiciels ont été utilisés: le logiciel SPSS pour le traitement des questions fermées et le logiciel NVivo 10 aux questions ouvertes. Enfin, les données obtenues à partir des questionnaires ont été croisées avec 
les données obtenues au SIASS maladies/UFT. Les résultats montrent que plus grande est l'intégration du projet de vie de l'enseignement à l'établissement, plus grande sera la QVT, même dans des conditions de travail défavorables. Inversement, plus grande est la distance du projet personnel/institutionnels, plus petite sera la QVT. Les facteurs relationnels sont directement impliqués dans la QVT des enseignants et l'adoption d'une politique de promotion et soutien à la fixation des enseignants contribue à la réduction de la même maladie.

Mots-clés: Rassembler; Travail des enseignants; La qualité de vie au travail; Établissements d'enseignement supérieur.

\section{Introdução}

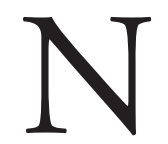

os últimos anos, os investimentos na educação superior no Brasil resultaram em um vultoso crescimento no número de docentes nas Instituições de Ensino Superior (IES), que entre 2003 e 2012 correspondeu a $40.958^{1}$ novas admissões nas diversas classes, fato que tem contribuído para a transformação do ambiente de trabalho universitário. Atualmente, o mundo do trabalho e as formas de acumulação do capital vêm se modificando aceleradamente, culminando num intenso processo de reestruturação produtiva com impactos nos mais diversos setores da sociedade. Nesse sentido, à medida que o processo de reestruturação produtiva se consolida, cada vez mais os trabalhadores são compelidos a se adaptar a um perfil baseado no paradigma da flexibilidade. (HARVEY, 2003) No âmbito do Ensino Superior, esse processo tem causado grande impacto sobre o trabalho docente.

Instaurou-se uma nova dinâmica dentro das universidades federais, que passaram a exigir do docente maior adaptabilidade às condiçóes de trabalho, bem como a mensurar o desempenho desses profissionais pelo número de publicaçóes produzidas por eles, pelos recursos captados para projetos de pesquisa e/ou extensão com agências de fomento, bem como pelo envolvimento do docente com as questôes institucionais e as comunidades que interagem no ambiente das universidades. Harvey (2003, p. 151) destaca que "[...] o próprio saber torna-se uma mercadoria-chave a ser produzida sob condiçôes que são elas mesmas cada vez mais organizadas em bases competitivas [...].”. Como consequência desse aumento da competitividade, observa-se, por um lado, o enfraquecimento da solidariedade entre os docentes, e de outro o surgimento de diversos sintomas institucionais como estresse, acidentes de trabalho, absenteísmo, adoecimento, presenteísmo, queda da produtividade, reclamaçóes sobre produtos e serviços de baixa qualidade, entre outros. 
Nesse contexto, a temática da QVT surgiu como a possibilidade de reduzir esse mal-estar organizacional, passando a ser pauta fundamental na agenda de diversos países e organizaçóes. ${ }^{2}$ Para a Organização Mundial da Saúde (1995, p. 407), qualidade de vida é definida como "[...] a percepção do indivíduo de sua posição na vida no contexto da cultura e sistema de valores nos quais ele vive e em relação aos seus objetivos, expectativas, padróes e preocupaçóes [...]". Neste estudo, adotou-se a concepção de QVT chamada contra-hegemônica. Essa abordagem possui um caráter eminentemente preventivo, que se baseia no enfoque da ergonomia da atividade aplicada à QVT. Nessa perspectiva, a QVT pode ser entendida, sob o prisma das organizaçóes, como

[...] um preceito de gestão organizacional que se expressa por um conjunto de normas, diretrizes e práticas no âmbito das condiçóes, da organização e das relaçôes socioprofissionais de trabalho que visa à promoçáo do bem-estar individual e coletivo, o desenvolvimento pessoal dos trabalhadores e o exercício da cidadania organizacional nos ambientes de trabalho. Sob a ótica dos trabalhadores, ela se expressa por meio das representaçóes globais (contexto organizacional) e específicas (situaçóes de trabalho) que estes constroem, indicando o predomínio de experiências de bem-estar no trabalho, de reconhecimento institucional e coletivo, de possibilidades de crescimento profissional e de respeito às características individuais. (FERREIRA, 2012, p. 219)

Dessa forma, o recurso epistemológico e metodológico consiste em colocar os trabalhadores no centro do processo de promoção da QVT e, ainda, retira os pontos geradores de mal-estar no trabalho, agindo em cinco categorias interdependentes: condiçóes de trabalho (infraestrutura), organização do trabalho, relaçóes socioprofissionais de trabalho, reconhecimento e crescimento profissional e elo trabalho-vida social.

Tendo como pano de fundo o cenário acima delimitado, o objetivo central desta pesquisa foi analisar a Qualidade de Vida no Trabalho (QVT) dos docentes da Universidade Federal do Tocantins (UFT), considerando os reflexos da reestruturação produtiva e a crescente precarização nas relações de trabalho, fato que tem alterado fortemente o contexto das Instituiçóes de Ensino Superior (IES) e a representação social que os docentes possuem acerca dessas instituiçôes.

A opção pela realização da pesquisa nessa instituição deve-se ao fato de essa universidade ter sido constituída dentro do contexto de expansão da educação superior, tendo sido instituída pela Lei no 10.032, de 23 de outubro de 2000, e ao fato de a UFT ter apresentado as maiores taxas de crescimento nos quadros docentes entres as universidades federais na Região Norte do País. ${ }^{3}$ 


\section{Métodos}

Buscando atender ao objetivo da pesquisa, foi formulado um Instrumento de Avaliação da QVT dos Docentes da UFT (IA_QVT/UFT), que se constituiu em uma ferramenta contendo itens quantitativos e qualitativos, disponibilizada digitalmente a todos os docentes da UFT no período de 6 de fevereiro de 2013 a 6 de março de 2013. O instrumento de avaliaçáo foi idealizado a partir de escalas psicométricas de mensuração do tipo likert de 10 pontos e complementado por questóes abertas, por meio das quais o respondente poderia complementar suas respostas acerca das diversas questóes levantadas no instrumento. Nesse sentido, o IA_QVT/UFT foi dividido em seçóes. As duas primeiras trataram da caracterizaçáo dos servidores ${ }^{4} \mathrm{e}$ das atividades dos docentes. A terceira seção inferiu os elementos de Qualidade de Vida no Trabalho por meio de um enunciado em que os respondentes assinalaram, de 0 a 10 , o número que melhor representasse sua opiniáo, considerando que o número 0 (zero) corresponde a "discordo totalmente" e o número 10 (dez) significa "concordo totalmente". As respostas obtidas no IA_QVT/UFT foram tratadas com uso de softwares, em que as questôes fechadas receberam tratamento por meio do uso do SPSS versão 15.0, e as questóes abertas foram tratadas por meio de análise estatística de dados textuais e submetidas à Análise de Conteúdo Categorial Temática (BARDIN, 1977), com auxílio do software NVivo 10.

\section{Resultados e discussões}

A partir do IA_QVT/UFT, buscou-se caracterizar alguns dos aspectos referentes ao trabalho docente que, acredita-se, têm influência sobre a QVT. Assim, pôde-se delimitar um conjunto expressivo de atividades realizadas pelos docentes que serviram de indicadores para as análises apresentadas na sequência.

Observa-se que, para além da atividade de ministrar aulas, os docentes desempenham diversas outras atividades que compóem o tripé Ensino, Pesquisa e Extensão (Gráfico 1). O conjunto dessas atividades ocupa toda a jornada de trabalho e, por vezes, as 40 horas semanais são ultrapassadas. Tal característica do trabalho faz que com $93 \%$ dos participantes da pesquisa trabalhem em seu tempo livre, o que conduz a uma situação de precarização da atividade do docente, que extrapola os limites da jornada de trabalho e invade o tempo que deveria estar sendo utilizado para outras atividades como o lazer e/ou a formação continuada. Nesse sentido, Borsoi (2012, p. 87) destaca que "[...] um computador conectado à internet e um telefone sáo suficientes para que mantenham seu elo com a instituição, onde quer que estejam [...]". 
Ao lançar um olhar sobre a dimensão subjetiva do trabalho docente, nossa análise centra-se nas fontes de vivência de bem-estar e mal-estar no âmbito das atividades desenvolvidas cotidianamente. A partir do levantamento do IA_ QVT/UFT, considerando as categorias de análise, já explicitadas, foram obtidos dados sobre o que os docentes consideram fontes de bem-estar em seu dia a dia de trabalho, expressos na Tabela 1.

\section{Gráfico 1}

Caracterização do Trabalho Docente Geral

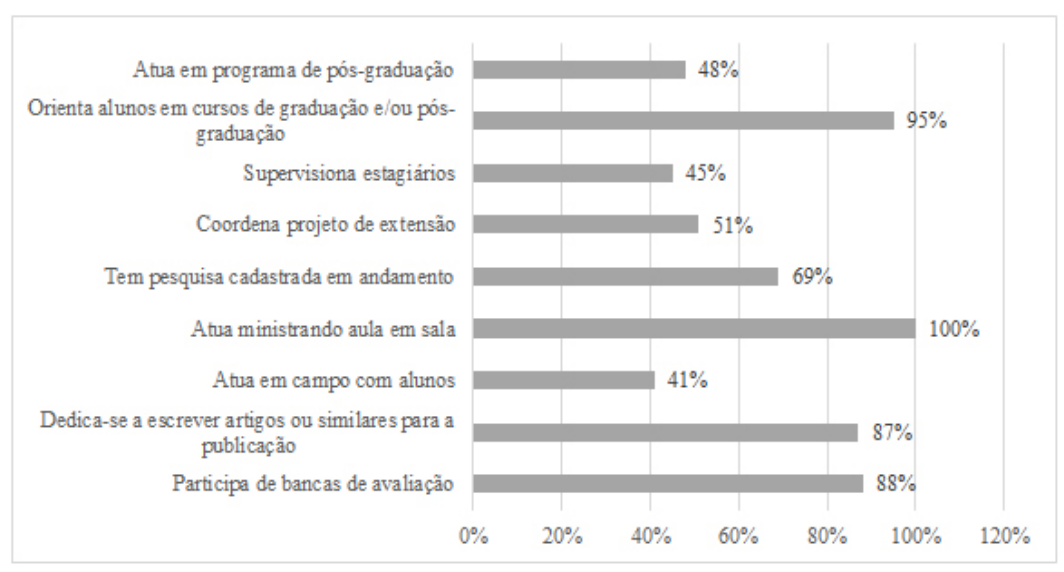

Como é possível perceber, as fontes de bem-estar para o docente da UFT estão predominantemente relacionadas à categoria "elo entre trabalho e vida social". A categoria representa o sentido do trabalho, a importância da instituição empregadora e a relação entre o trabalho e a vida social do sujeito. Desse fato decorre a constatação de que o bem-estar no trabalho, para os professores da universidade pesquisada, encontra-se implicado com a formaçáo da sua identidade, enquanto docente, reafirmada via instituição e com o projeto de vida do sujeito que se relaciona com o ideal da profissão: atuar no campo da ciência para a produção do conhecimento, objetivando a transformação da realidade social.

Sabe-se que a identidade profissional se constitui por meio da revisão permanente do sentido social da profissão, quando o exercício profissional faz sentido para o sujeito e permite-lhe ser, de fato, criativo. Nesse sentido, a atividade profissional constitui-se uma fonte de bem-estar, não só pelo sentido do trabalho, mas pela realização referente a um projeto de vida do sujeito. (ANTUNES, 1999) Vale destacar que as falas sobre a categoria "relaçôes socioprofissionais de trabalho" como fonte de bem-estar são, predominantemente, a respeito da relação dos docentes com seus discentes. 


\section{Tabela 1}

Fontes de bem-estar no trabalho - IA_QVT/UFT

\begin{tabular}{|c|c|c|c|}
\hline Categoria & $\begin{array}{c}\text { Frequência } \\
\text { Absoluta }\end{array}$ & \begin{tabular}{|c|} 
Frequência \\
Relativa \\
\end{tabular} & Exemplo de Verbalização \\
\hline $\begin{array}{c}\text { Condição de } \\
\text { Trabalho e Suporte } \\
\text { Organizacional }\end{array}$ & 6 & $4 \%$ & $\mathrm{O}$ ambiente natural \\
\hline $\begin{array}{l}\text { Organização do } \\
\text { Trabalho }\end{array}$ & 11 & $8 \%$ & $\begin{array}{l}\text { A autonomia em relação à } \\
\text { flexibilidade do horário de trabalho, ou } \\
\text { seja, sei que tenho que cumprir uma } \\
\text { determinada carga horária de trabalho } \\
\text { semanal, mas posso fazer isso em } \\
\text { horários alternados, sem ter que bater } \\
\text { o ponto na chegada e saida }\end{array}$ \\
\hline $\begin{array}{c}\text { Relações } \\
\text { Socioprofissionais } \\
\text { de Trabalho }\end{array}$ & 37 & $25 \%$ & $\begin{array}{l}\text { A troca com os alunos e a vivência } \\
\text { com alguns bons amigos. Hoje, boa } \\
\text { parte das minhas relações sociais são } \\
\text { com amigos feitos na UFT }\end{array}$ \\
\hline $\begin{array}{c}\text { Reconhecimento e } \\
\text { Crescimento } \\
\text { Profissional }\end{array}$ & 6 & $4 \%$ & $\begin{array}{l}\text { O reconhecimento dos alunos e } \\
\text { comunidade externa do meu trabalho }\end{array}$ \\
\hline $\begin{array}{c}\text { Elo entre } \\
\text { Trabalho e Vida } \\
\text { Social }\end{array}$ & 85 & $59 \%$ & $\begin{array}{l}\text { Satisfação de um trabalho bem-feito e } \\
\text { o sentimento de auxiliar para o } \\
\text { crescimento pessoal e intelectual das } \\
\text { pessoas, além do auxilio à } \\
\text { comunidade }\end{array}$ \\
\hline
\end{tabular}

No que tange às fontes de mal-estar no trabalho, os resultados obtidos estão relacionados na Tabela 2. Os dados expostos reforçam uma realidade já por demais debatida, qual seja a precarizaçáo objetiva do trabalho em muitas universidades federais brasileiras que, historicamente, se constitui pela falta dos recursos básicos no que se refere aos equipamentos arquitetônicos, ambiente físico e instrumental de trabalho. Mesmo considerando os investimentos realizados nos últimos anos pelo governo brasileiro, por intermédio do Programa de Apoio a Planos de Reestruturação e Expansão das Universidades Federais (Reuni), percebe-se que as condiçóes de trabalho e suporte organizacional da universidade têm sido para os docentes fonte de mal-estar no trabalho. Em igual medida, observa-se que elementos associados às "relaçôes socioprofissionais de trabalho", anteriormente elencadas como fonte de bem-estar no trabalho pelos docentes (Tabela 1), surgem aqui como fonte de mal-estar. Analisando as falas dos docentes, é possível perceber que o mal-estar tende a estar fortemente ligado à competitividade entre os docentes e as relaçóes interpessoais decorrentes desse ambiente competitivo. 


\section{Tabela 2}

Fontes de mal-estar no trabalho - IA_QVT/UFT

\begin{tabular}{|c|c|c|c|}
\hline Categoria & $\begin{array}{c}\text { Frequência } \\
\text { Absoluta }\end{array}$ & $\begin{array}{c}\text { Frequência } \\
\text { Relativa }\end{array}$ & Exemplo de Verbalização \\
\hline $\begin{array}{c}\text { Condição de } \\
\text { Trabalho e Suporte } \\
\text { Organizacional }\end{array}$ & 60 & $38 \%$ & $\begin{array}{l}\text { A falta de infraestrutura como: não há } \\
\text { laboratórios para aulas práticas com os } \\
\text { alunos, falta de sala de professores, falta de } \\
\text { sala de aula, falta de data show na sala de } \\
\text { aula, falta de equipamentos e acessórios para } \\
\text { alguns projetos de extensão e para realização } \\
\text { de eventos, parco acervo da biblioteca }\end{array}$ \\
\hline $\begin{array}{c}\text { Organização do } \\
\text { Trabalho }\end{array}$ & 27 & $17 \%$ & $\begin{array}{l}\text { O acúmulo de atividades e o cansaço mental } \\
\text { que isso me proporciona, uma vez que ele se } \\
\text { reflete no meu corpo. O acúmulo da docência } \\
\text { na graduação, na especialização e no } \\
\text { mestrado e todas as atividades envoltas a } \\
\text { essas responsabilidades gera uma sobrecarga, } \\
\text { que não poucas vezes me suprime o direito } \\
\text { de ter sábados, domingos ou feriados, pois } \\
\text { tenho que trabalhar nesses dias para poder ter } \\
\text { uma qualidade significativa nas ações que vou } \\
\text { empreender }\end{array}$ \\
\hline $\begin{array}{c}\text { Relações } \\
\text { Socioprofissionais } \\
\text { de Trabalho }\end{array}$ & 60 & $38 \%$ & $\begin{array}{l}\text { As implicâncias de colegas competitivos, } \\
\text { arrogantes ou que usam de má-fé, com } \\
\text { calúnias, insinuações, difamações, ataques } \\
\text { verbais, agressividade. Acho mesmo que isso } \\
\text { tudo caracteriza um certo adoecimento de } \\
\text { natureza psicológica ou moral }\end{array}$ \\
\hline $\begin{array}{c}\text { Reconhecimento e } \\
\text { Crescimento } \\
\text { Profissional }\end{array}$ & 6 & $4 \%$ & $\begin{array}{l}\text { Infelizmente a educação não é muito } \\
\text { valorizada como um todo }\end{array}$ \\
\hline $\begin{array}{c}\text { Elo entre } \\
\text { Trabalho e Vida } \\
\text { Social }\end{array}$ & 4 & $3 \%$ & $\begin{array}{l}\text { Quando percebo que as pessoas não } \\
\text { internalizaram a missão e a visão da UFT e o } \\
\text { seu papel junto à sociedade }\end{array}$ \\
\hline
\end{tabular}

No mesmo sentido, observou-se que as "relaçôes socioprofissionais de trabalho" sofrem prejuízos em razão da falta de "condição de trabalho e suporte organizacional", pois as diferenças de condiçóes de trabalho entre os profissionais acirram a competitividade entre os pares e, muitas vezes, a conquista de um direito por um docente transmuta-se em "privilégio" perante os demais. A falta de espaços institucionais adequados para a convivência entre os docentes resulta em um desconhecimento sobre as atividades desenvolvidas pelos mesmos, fazendo que os docentes não saibam, ou não tenham clareza, das atividades desenvolvidas por seus colegas. Tal fato, em muitos momentos, é percebido e vivenciado por muitos docentes como uma situação de injustiça. Isso é observado nas falas dos docentes 
que acusam outros colegas de ser menos comprometidos, ou se queixam de estar sobrecarregados de atividades enquanto outros profissionais "quase não aparecem na universidade". O ambiente conflitivo não passa despercebido pelos docentes, que se manifestam em relação a essa questão. "Creio que a falta de informação gera criticas e açóes destrutivas por parte de alguns colegas" [sic]. As manifestações revelam que a falta de integração pode gerar impactos negativos nas relaçóes entre os docentes. Fala-se, aqui, do enfraquecimento dos laços de solidariedade, elemento essencial cuja função primordial é permitir a integração socioprofissional dos sujeitos. Torna-se evidente a necessidade de adoção de Políticas de Promoção e Suporte à QVT que atuem contra as múltiplas fontes de sofrimento, garantindo o atendimento de todos os fatores.

$\mathrm{Na}$ tentativa de compreender melhor as fontes de bem-estar e de mal-estar no trabalho, serão analisadas as médias obtidas no IA_QVT/UFT (Figura 1 e Gráfico 2).

\section{Figura 1}

Escala para avaliação de mal-estar e bem-estar no trabalho

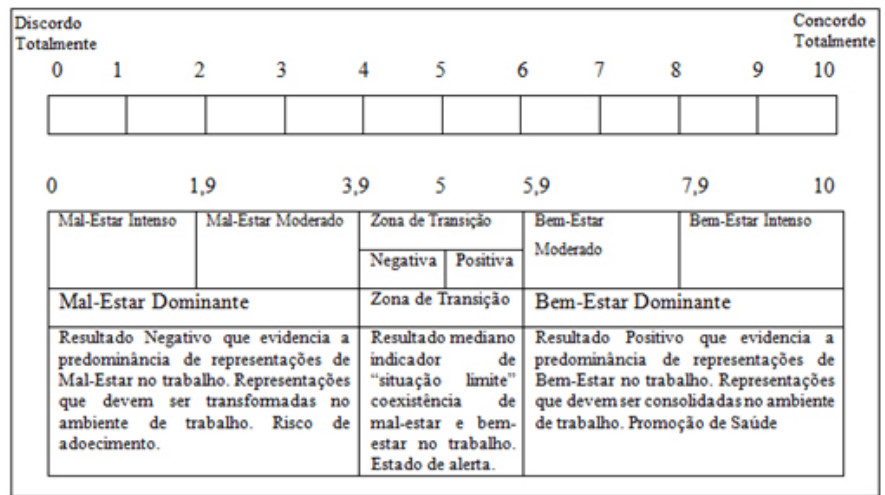

Fontes: Ferreira, 2012, p. 210.

Numa visão mais geral, a situação esboçada pelo IA_QVT/UFT é bastante favorável. Nessa perspectiva, 78\% dos respondentes estão vivenciando uma QVT correspondente à zona de bem-estar. No entanto, observando a distribuição das médias obtidas no IA_QVT/UFT, um número representativo, aproximadamente $22 \%$ dos respondentes, está em risco de adoecimento ou tendendo ao adoecimento. A partir da análise dos itens envolvidos em cada categoria é possível uma melhor aproximação da realidade da QVT docente, como será visto na sequência. 
Qualidade de vida no trabalho e adoecimento no cotidiano

\section{Gráfico 2}

Distribuição do resultado global de QVT

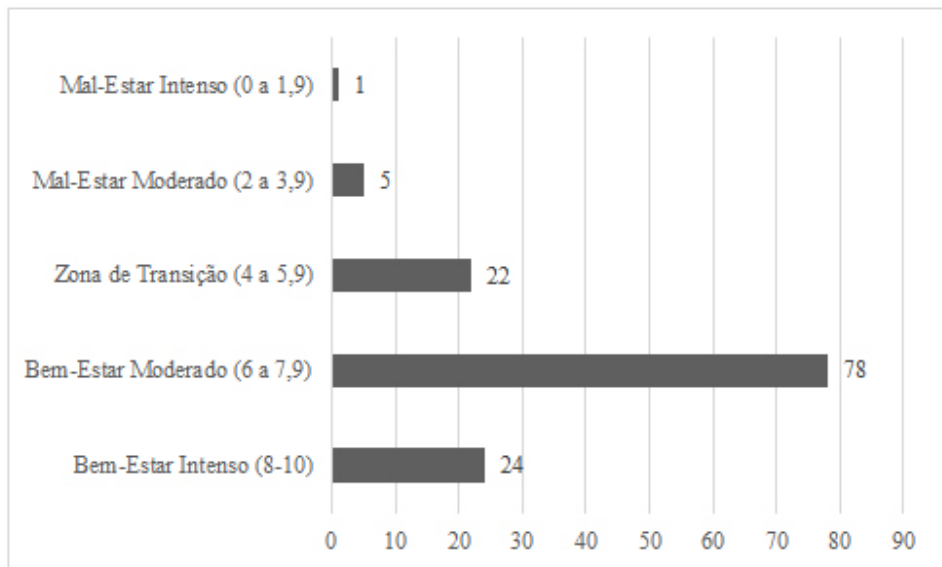

\section{Gráfico 3}

Distribuição dos resultados sobre Condiçôes de Trabalho

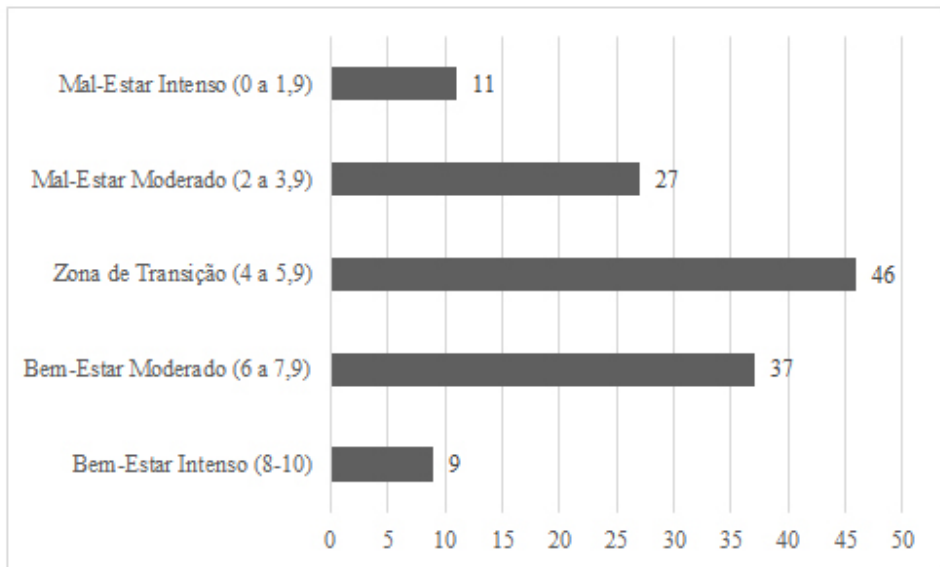

A categoria "condiçóes de trabalho" pode ser compreendida como um dos principais eixos de investigação dos contextos de trabalho e, quando são avaliadas como inadequadas, podem levar a vivências de mal-estar no trabalho. (PACHECO, 2011) Essa categoria tem sido destacada como um elemento indispensável à promoçáo da Qualidade de Vida no Trabalho, na busca de reduzir os riscos à 
segurança e à saúde dos trabalhadores e facilitar o processo de sua adaptação às novas exigências do trabalho. ${ }^{5}$

De modo geral, o Gráfico 4 indica a situação dos docentes em relação à média dos itens avaliados anteriormente na categoria "organização do trabalho".

\section{Gráfico 4}

Distribuição dos resultados sobre Organização do Trabalho

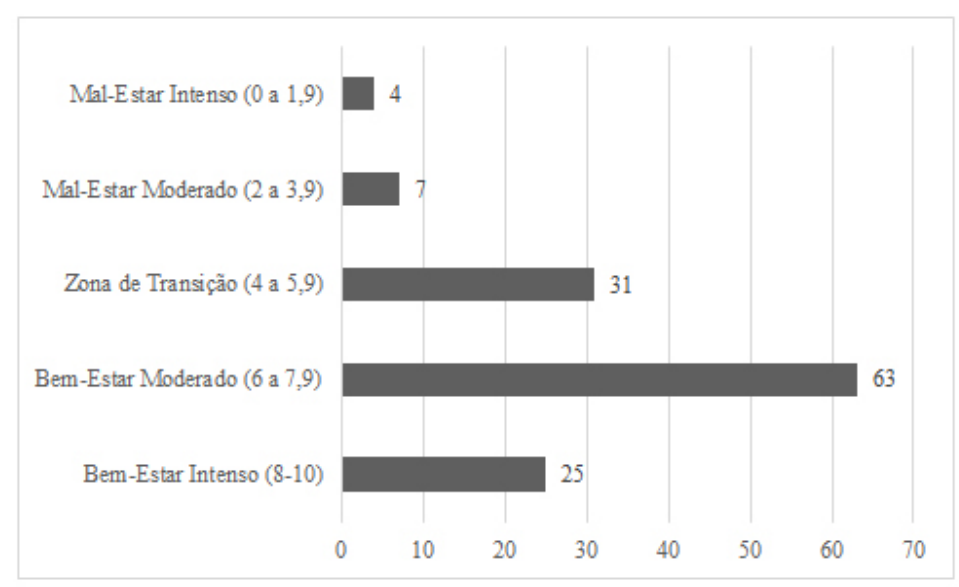

Observa-se que existe um número representativo de docentes em risco de adoecimento ou tendendo ao adoecimento devido ao mal-estar relacionado à categoria "organização do trabalho". Depois da categoria "condiçóes de trabalho" os aspectos relacionados à organização, ou seja, à estrutura, são imprescindíveis para o bem-estar no trabalho e, consequentemente, para a QVT. Em linhas gerais, as condiçóes de trabalho atendem às necessidades materiais/fisiológicas para o trabalho, e a organização do trabalho organiza a vida subjetiva do trabalhador na instituição, permitindo-lhe vislumbrar e consolidar seu projeto de vida na instituição a longo prazo - por isso a importância do conhecimento dos objetivos da instituição, a percepção de justiça a respeito da carga de trabalho, da jornada de trabalho, das regras institucionais, do plano de carreira, das atividades desenvolvidas etc.

No Gráfico 5 pode-se observar a distribuição das médias de resposta sobre a categoria "relaçóes socioprofissionais de trabalho" no IA_QVT/UFT. 


\section{Gráfico 5}

Distribuição dos resultados sobre Relações

Socioprofissionais de Trabalho

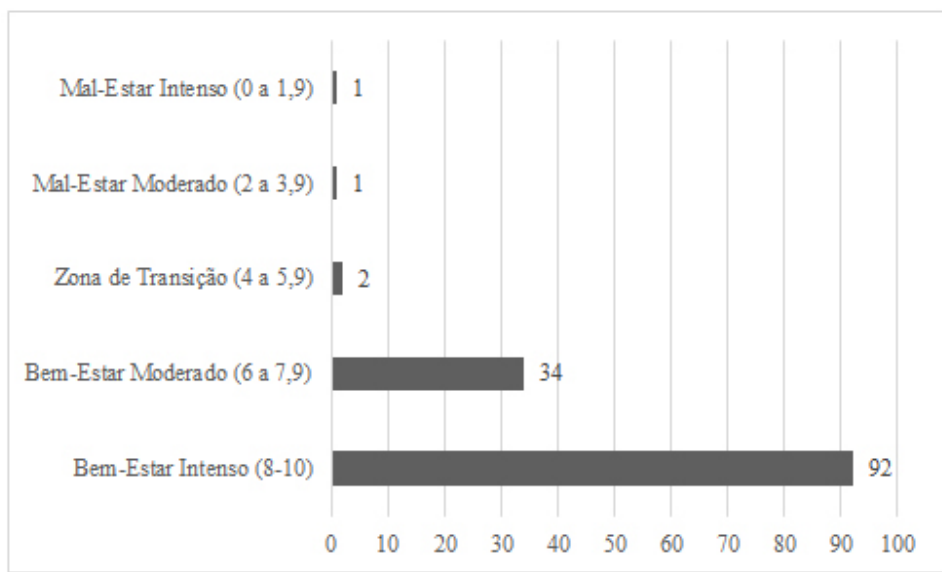

É possível afirmar que as relaçóes socioprofissionais, para os docentes que atuam apenas na graduação, ocorrem basicamente na sala de aula e nas atividades vinculadas ao curso de graduação ao qual pertencem. Entretanto, como se observou anteriormente, muitos docentes estão vinculados a trabalhos e/ou cargos administrativos dentro da universidade, fato que os conduz a vivenciarem relações hierárquicas mais densas além de um complexo organograma. Há ainda um considerável número de docentes vinculados a cursos de pós-graduação, o que implica uma nova dinâmica nas referidas relaçóes. Dessa forma, entende-se que à medida que as atividades do docente vão ficando mais complexas, suas relaçóes socioprofissionais na universidade tornam-se, de forma análoga, mais complexas.

Uma vez que muitos dos docentes em exercício na instituição pesquisada provêm de outros estados ou países, observou-se que as relações socioprofissionais passam a ter um peso maior em sua vida. Para muitos deles, o conjunto dessas relaçóes torna-se, no plano privado, o conjunto de suas relaçóes sociais pelo fator de proximidade. Nessas condições, os sujeitos não distinguem ou separam o conjunto de relaçóes profissionais vivenciadas na universidade das relaçóes sociais vividas no plano privado. Assim, os docentes não vivenciam mais todas essas relaçóes como pertencentes a espaços diferenciados, cada conjunto com suas regras próprias, mas as vivenciam com advindas de uma dimensão única, híbrida, que se forma da fusão de ambas as esferas: a profissional e a pessoal.

Como consequência, observa-se que, por vezes, conflitos da esfera privada se desdobram dentro da instituição e conflitos da vida institucional podem 
ser fortemente vivenciados em âmbito privado. Nesse sentido, para além do saldo positivo apresentado pela categoria "relaçóes socioprofissionais de trabalho", as manifestaçóes dos docentes indicaram que a dinâmica vida profissional/vida privada afeta diretamente as relaçóes, como é possível notar nas falas a seguir.

Fala 01: "Infelizmente, a gramática política predominante que rege tais relações não é de ordem profissional e republicana e sim de ordem paternalista e seus derivados".

Fala 02: "Problemas de confusão de divergências no campo administrativo com supostas divergências no campo das relaçôes pessoais e vice-versa”.

Fala 03: "Sempre tivemos um ambiente de harmonia, mas acho também que precisamos de um ambiente de convivência maior, mais aproximação".

Fala 04: "O clima na UFT é pouco profissional. Sinto como se estivéssemos todos numa cidade do interior, daquelas bem pequeninhas, pois os fuxicos, as discordâncias estâo sempre no nível pessoal. As pessoas têm dificuldade de trabalhar em conjunto, de pensar coletivamente. $\mathrm{O}$ resultado é um trabalho individual, descompassado da política da instituição, do curso. Cada um faz o que acha que deve fazer e sem sintonia o curso parece um conjunto de pessoas com instrumentos, mas que não conseguem compor uma orquestra”.

Diante dos dados e das falas apresentadas, é importante tecer algumas consideraçóes adicionais. Se, por um lado, a falta de espaços institucionais para o convívio profissional pode reforçar a dinâmica vida profissional/vida privada, indicando, novamente, a necessidade de Políticas de Promoção e Suporte à QVT, por outro as médias elevadas obtidas no IAQVT-UFT não permite concluir que o bom desempenho se refere a uma relação de boa convivência, uma vez que, como observado, eventualmente esses colegas tornam-se amigos, companheiros, cônjuges, compadres etc. Assim, as relaçóes socioprofissionais passam a ser avaliadas tendo como elemento de mediaçáo um conjunto de interaçóes oriundas da esfera privada. Em outras palavras, pode-se dizer que, nesses casos, a avaliação profissional encontra-se permeada por sentimentos e subjetividades advindas de um campo constitutivo de sociabilidades distinto do campo das solidariedades e relacionamentos laborais.

No Gráfico 6, pode-se observar a distribuição das médias de resposta sobre a categoria "reconhecimento e crescimento profissional' no IA_QVT/UFT. 


\section{Gráfico 6}

Distribuição dos resultados sobre Reconhecimento e

Crescimento Profissional

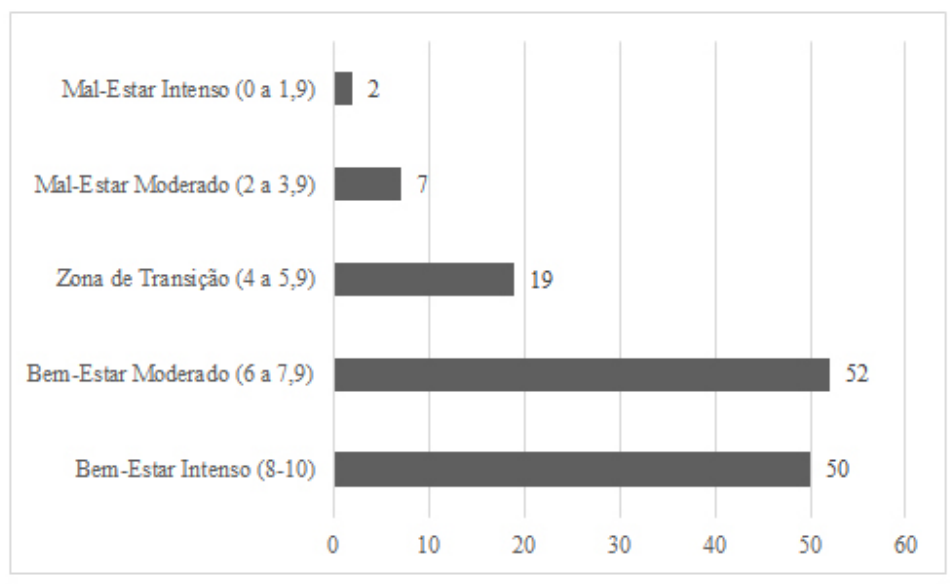

A categoria "reconhecimento e crescimento profissional", para os docentes pesquisados, relaciona-se fortemente com três eixos: instituição, comunidade acadêmica e comunidade científica. Isso porque cada um desses eixos tem grande importância, resguardadas suas diferenças. O reconhecimento institucional está fortemente ligado às questóes legais e se refere, em grande medida, às formas de progressão na carreira de docente; o reconhecimento da comunidade acadêmica se relaciona intensamente ao reconhecimento por parte do corpo discente da universidade, ligado ao conjunto de relaçóes que ocorrem no âmbito das salas de aulas, do desenvolvimento de projetos de pesquisa e ou de extensão; por fim, o reconhecimento por parte da comunidade científica vincula-se ao reconhecimento obtido entre os pares, seja por meio da produção qualificada de artigos, projetos e/ou pesquisas.

As três formas de reconhecimento apresentadas encontram correspondência com as formas de reconhecimento desenvolvidas por Axel Honneth (2003) em sua teoria do reconhecimento. Para o sociólogo, os sujeitos encontram-se em uma constante luta por reconhecimento nas diversas esferas da vida social. Nessa perspectiva, existem três formas distintas de reconhecimento: a) as relaçóes primárias, cujas formas de reconhecimento são o amor e a amizade; b) as relaçóes legais, cujas formas de reconhecimento são as identificadas com os direitos; e c) as comunidades de valor, cuja forma de reconhecimento é a solidariedade. Para cada uma dessas dimensóes - amor, direito, solidariedade - existe uma relação prática 
do sujeito com o self, relaçóes definidas respectivamente como autoconfiança básica, autorrespeito e estima social.

\begin{tabular}{c|c|c}
\hline $\begin{array}{c}\text { Âmbito de } \\
\text { Reconhecimento }\end{array}$ & $\begin{array}{c}\text { Formas de } \\
\text { Reconhecimento }\end{array}$ & $\begin{array}{c}\text { Âmbito de } \\
\text { Reconhecimento dos } \\
\text { Docentes }\end{array}$ \\
\hline Relações Primárias & Amor e Amizade & Sala de Aula, Projetos \\
$\begin{array}{c}\text { Relações Legais } \\
\text { Comunidades de } \\
\text { Valor }\end{array}$ & Direitos & Progressão na Carreira \\
\hline
\end{tabular}

Observando o Gráfico 6, percebe-se que há mais docentes em zona de mal-estar e transição na categoria de "reconhecimento e crescimento profissional" do que na categoria de "relaçôes socioprofissionais de trabalho". Nota-se na análise das médias dos itens que há maior sentimento de reconhecimento dos docentes relacionado aos alunos.

Fala 05: "Não trabalho para ter reconhecimento dos colegas, mas sim dos meus alunos".

Fala 06: "As atividades executadas junto aos alunos bem com junto à comunidade são reconhecidas".

Fala 07: "Por parte dos alunos tenho reconhecimento do meu trabalho, nesse caso não tenho do que reclamar. Minha experiência como professor não foi construída apenas na UFT. Por ter domínio de sala de aula e gostar da atividade docente me sinto bem nesse aspecto, quanto aos colegas, acho que nem todos conhecem meu pensamento nem o meu potencial".

Sobre o reconhecimento por parte dos colegas, observa-se nas falas que este está sempre relacionado à competitividade e afinidade entre pares. As verbalizaçóes dos docentes nesse sentido deixam transparecer ainda mais a penetração da lógica da reestruturação produtiva nas IES.

Fala 08: "Não há reconhecimento uma vez que não pertenço ao grupo de poder instituído".

Fala 09: "O ambiente entre os colegas nem sempre é bom. Por alguma degeneração do processo, há em alguns momentos 
bastante competitividade e hostilidade que me afetam bastante. Os que exercem certa liderança intelectual e política são sempre alvo dos que não produzem ou não conseguem distinguir-se senão pela agressividade e destemperança. Por parte dos superiores e da maior parte dos colegas, contudo, há respeito e reconhecimento".

Fala 10: "Trabalho extremamente individualizado e personalista. Não há política de reconhecimento de mérito profissional”.

Por fim, há o questionamento sobre se a universidade possibilita desenvolvimento e crescimento profissional. Embora a média geral tenha indicado bem-estar intenso em relação às possibilidades de desenvolvimento e crescimento profissional proporcionados pela instituição, alguns docentes destacam que tal crescimento passa pela participação em eventos fora do estado, que muitas vezes tem que ser custeada por eles próprios, em vista das limitaçóes da instituição.

Fala 11: "A UFT abre muitas possibilidades para os professores. Falta muita coisa, mas ainda assim acho que a Universidade faz o seu papel nesse sentido".

Fala 12: "A UFT é uma universidade nova e por isso apresenta muitas oportunidades de crescimento profissional".

Fala 13: "Poderia haver um apoio mais consistente para pesquisadores participarem de eventos científicos fora do estado. O edital para isso contempla um número reduzidíssimo de verba, a pós-graduação recebe verba insuficiente para todas as demandas e, assim, temos literalmente que pagar para cumprir um cronograma mínimo de participação em eventos em outras instituiçōes. Considerando que estamos situados geograficamente bem distante de grandes universidades, temos sofrido bastante financeiramente para garantir a visibilidade de nossas produçóes e atualizaçáo diante das pesquisas desenvolvidas por nossos pares de outras IES".

Em relação ao aspecto abordado, destaque-se que no Manual de Estágio Probatório Docente ${ }^{6}$ um dos pontos que recebe mais atenção no quesito avaliação é justamente a produtividade. Assim, o docente será cobrado por sua produtividade mesmo que a instituição não possa lhe garantir as condições necessárias para tal. Nota-se ainda que para os docentes o reconhecimento profissional passa pela efetivação de seu projeto de vida na instituição, sendo este uma fonte de bem-estar no trabalho. A exemplo disso tem-se a verbalização do docente:

Fala 14: "Mas esse reconhecimento é também pessoal. Ou seja, a relação com os alunos e meus projetos, meus conhecimentos na 
sociedade me oportunizam isso, mas não é um reconhecimento institucional. Não é em função da instituição, mas do meu trabalho pessoal".

No Gráfico 7 pode-se observar a distribuição das médias de resposta sobre a categoria "elo entre trabalho e vida social" no IA_QVT/UFT.

\section{Gráfico 7}

Distribuição dos resultados sobre Elo entre Trabalho e Vida Social

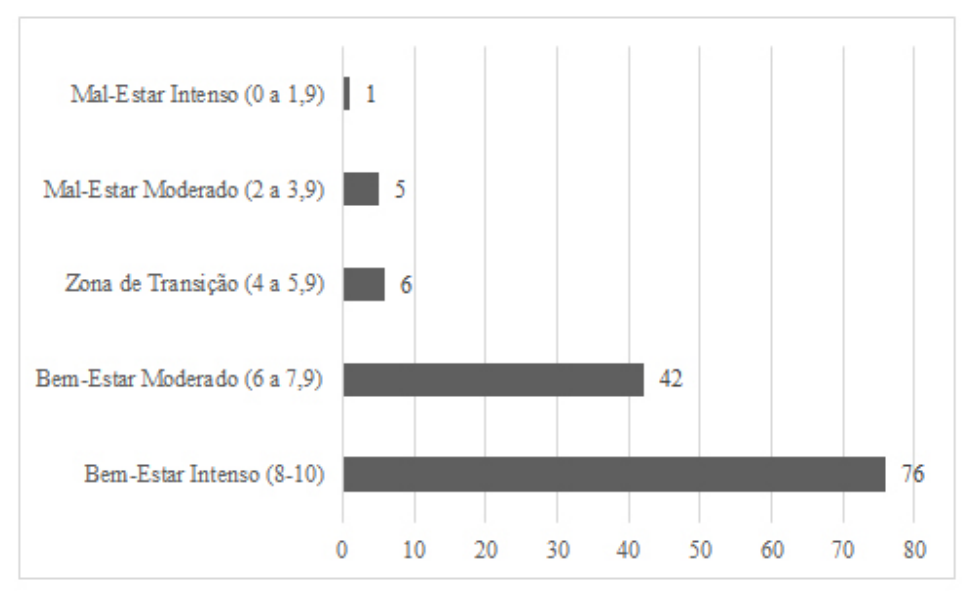

O "elo entre o trabalho e a vida social" constitui muito provavelmente a categoria que permite compreender, de maneira mais ampla, como o trabalho se estabelece enquanto um projeto de vida fonte de identidade e autorrealização para os docentes.

Algumas das verbalizaçôes referentes a esta categoria exemplificam essa dimensão.

Fala 15: "Foi um objetivo traçado enquanto estudante me tornar professor de Universidade Federal”.

Fala 16: "Sempre quis ser professor e trabalhar com pesquisa. A UFT me possibilita isso".

Fala 17: "O principal degrau da minha vida, minha formação superior, meu mestrado e uma possibilidade grande de um doutorado. A UFT me fez crescer como profissional". 
Percebe-se, assim, a grande importância do elo entre o trabalho e a vida social na formação da identidade do docente, e esse papel extrapola questóes institucionais. $\mathrm{O}$ projeto de vida tem relação com o sentido do trabalho para o sujeito e é singular para cada indivíduo; a ideia de atuar como docente evoca utilidade social. Algumas verbalizações de docentes quando perguntados sobre suas fontes de bem-estar no trabalho evidenciam essa reflexão:

Fala 18: "A possibilidade de contribuição social e de mudança da realidade na qual estou inserida, fazer parte da construção desta universidade, atuando no tripé ensino, pesquisa e extensão”.

Fala 19: "Estudar o que gosto, realizar projetos e incluir esses projetos como parte de minha vida".

Fala 20: "A possibilidade de relacionar os meus estudos e crescimento pessoal, espiritual com as minhas atividades como docente, como pesquisadora e como membro participante da vida da comunidade portuense".

Caso o sentido desse trabalho se perca para o indivíduo em razão de $\operatorname{algum(ns)~fator(es)~na~gênese~das~vivências~de~bem-estar~e~mal-estar~no~trabalho,~}$ ficam comprometidos o projeto de vida e, consequentemente, a identidade do docente, o que pode resultar em adoecimento.

O relatório do SIAPE-Saúde revela que, no período compreendido entre 1o de junho de 2011 e 31 de dezembro de 2012, houve 2.324 dias de afastamento entre os docentes. Por meio da análise do SIASS/UFT, averiguou-se que dos 3.862 servidores federais no Estado do Tocantins, os docentes do nível superior ocupam o terceiro lugar em afastamentos do serviço por motivo de saúde. O número pode ser ainda mais preocupante se for considerada a falha nos registros da UFT de afastamento por motivo de saúde: as coordenaçóes dispensam a apresentação de atestados médicos dos docentes, em razão da flexibilidade do cargo, e os docentes repóem suas aulas quando recobram a saúde, não havendo, portanto, registro de seu afastamento.

Em relação às causas dos afastamentos ${ }^{7}$, de acordo com o sistema SIAPE-Saúde de maneira global, no período analisado prevaleceram os afastamentos em razão de transtornos relacionados à saúde mental ou CID "F", com 19\%; seguidos por afastamentos representados pelo CID "S", que se relaciona a fraturas e lesóes, com 15\%; em seguida observa-se que 14\% dos afastamentos relacionam-se a doenças do sistema osteomuscular e do tecido conjuntivo (CID "M"). 


\section{Considerações finais}

O estudo de caso da QVT dos docentes na Universidade Federal do Tocantins permitiu observar que a expansão da universidade náo foi acompanhada de melhorias das condiçóes de trabalho dos docentes, uma realidade que não é diversa das outras Instituiçóes de Ensino Superior. Segundo a avaliação do Sindicato Nacional dos Docentes das Instituiçóes de Ensino Superior (Andes-SN) ${ }^{8}$, os problemas já existentes nas IES se agravaram com o Reuni: infraestrutura inadequada, longas jornadas, más condiçôes de trabalho e falta de número suficiente de professores são apenas alguns dos pontos destacados. Com base no estudo sobre a UFT, evidenciou-se que, de modo geral, a universidade não possui Políticas de Promoção e Suporte à QVT dos servidores e dos docentes, especificamente.

Nesse sentido, nota-se que o movimento de precarização das condições de trabalho acaba por modificar a atividade docente e, consequentemente, a dinâmica do relacionamento entre os pares, fato que gera um mal-estar em relaçáo à divisão do trabalho e à sobrecarga do mesmo.

Por meio do IA_QVT/UFT, comprovou-se, de modo geral, que a QVT oferecida pela instituição não dá sustentação ao exercício docente, e este, por sua vez, sustenta-se por fatores subjetivos relacionados ao sentido do trabalho, à identidade docente, ao projeto de vida do sujeito enquanto professor e à relaçáo docente-aluno. As médias mais baixas indicadas pelos docentes correspondem às condiçóes de trabalho (estrutura física e instrumental) e suporte organizacional oferecidos pela UFT. Observa-se, ainda, uma avaliação regular sobre a organização do trabalho. Por fim, as médias mais elevadas foram obtidas em razão das relaçóes socioprofissionais e do elo entre trabalho e a vida social, ou seja, a inserçäo social e o sentido do trabalho para esse sujeito.

A falta de infraestrutura dentro dos campi da universidade para o pleno exercício da docência (ensino, pesquisa e extensão) contribui para minar as relaçóes socioprofissionais de trabalho, aumentando a competitividade entre pares e dirimindo os limites entre público e privado necessários para o bom convívio no ambiente profissional. Assim, observa-se que, no geral, os docentes sustentam seu trabalho com base em fatores subjetivos e faltam Políticas de Promoção e Suporte à QVT que promovam "Condiçôes de Trabalho e Suporte Organizacional", "Organizaçấo do Trabalho", "Reconhecimento Socioprofissional no Trabalho" que, consequentemente, melhorem as "Relaçóes Socioprofissionais de Trabalho" e o "Elo entre Trabalho e Vida Social". Em outras palavras, medidas que atuem a favor da promoção do bem-estar no trabalho e, ao mesmo tempo, contra as fontes causadoras de mal-estar. 
Qualidade de vida no trabalho e adoecimento no cotidiano

\section{Notas}

1. Dados do MEC disponíveis em <http://reuni.mec.gov.br>. Data de acesso: 2 set. 2013.

2. Sobre esse ponto, vale destacar a Agenda Nacional de Trabalho Decente e a declaração da OIT sobre justiça social para uma globalização equitativa, ambos em defesa de uma abordagem de QVT de parâmetros preventivos focados na promoçấo de bem-estar no trabalho. (BERG; RIBEIRO, 2010)

3. Para um maior detalhamento desse ponto ver: <http://portal.mec.gov.br/expansao/>.

4. Considerando os objetivos deste artigo e sua extensão, não iremos explorar em profundidade as questóes relativas à caracterização dos docentes da UFT.

5. Para um maior detalhamento dessa questão, ver Ferreira (2008).

6. Disponível em: <http://www.uft.edu.br>. Acesso em: 2 dez. 2012.

7. Utilizou-se aqui a Classificação Internacional de Doenças e Problemas Relacionados à Saúde (CID-10).

8. Disponível em: <http://agenciabrasil.ebc.com.br/noticia/2013-05-05/expansao-de-universidades-federais-nao-acompanhou-melhoria-das-condicoes-de-trabalho-de-docentes-diz>. Acesso em: 9 maio 2013.

\section{Referências}

ANTUNES, R. Os sentidos do trabalho: ensaio sobre a afirmação e a negação do trabalho. São Paulo: Boitempo, 1999.

BARDIN, L. Análise de conteúdo. Tradução Luís Antero Reto e Augusto Pinheiro. Lisboa: Ediçôes, 1977.

BERG, J.; RIBEIRO, J. Evolução recente do Trabalho Decente no Brasil: avanços e desafios. In: Encontro Nacional de Estudos Populacionais da Associação Brasileira de Estudos Populacionais. 16., 2010. Anais... Campinas: Abep/Unicamp, 2010.

BORSOI, I. C. F. Trabalho e produtivismo: saúde e modo de vida de docentes de instituiçôes públicas de Ensino Superior. Cadernos de Psicologia Social do Trabalho, v. 15, n. 1, p. 81-100, 2012.

FERREIRA, M. C. O que pensam os trabalhadores franceses sobre as novas exigências do trabalho? In: ROSSO, S. D.; FORTES, J. A. A. S. (Org.) Condiçôes de trabalho no limiar do século XXI. Brasília: Época, 2008.

. (Org.). Qualidade de Vida no Trabalho: uma abordagem centrada no olhar do trabalhador. 2. ed. Brasília: Paralelo, 2012.

HONNETH, A. Luta por reconhecimento: a gramática moral dos conflitos sociais. São Paulo: Editora 34, 2003.

HARVEY, D. A condição pós-moderna. 12. ed. São Paulo: Loyola, 2003. 
WHO. World Health Organization Quality of Life Assessment (WHOQOL): position paper from the World Health Organization. Social Science and Medicine, v. 41, n. 10, p. 403-409, 1995.

PACHECO, V. A. Qualidade de vida no trabalho, bem-estar e mal-estar sob a ótica de trabalhadores de uma agência reguladora no Brasil. 2011. 134f. Dissertação (Mestrado em Psicologia Social, do Trabalho e das Organizaçóes) - Universidade de Brasília, Brasília, 2011.

Recebido em 24 de setembro de 2013.

Aprovado em 02 de julho de 2014.

DOI: http://dx.doi.org/10.1590/ES0101-73302015124201 